Supplement of Hydrol. Earth Syst. Sci., 22, 373-390, 2018

https://doi.org/10.5194/hess-22-373-2018-supplement

(C) Author(s) 2018. This work is distributed under

the Creative Commons Attribution 4.0 License.

(c) (1)

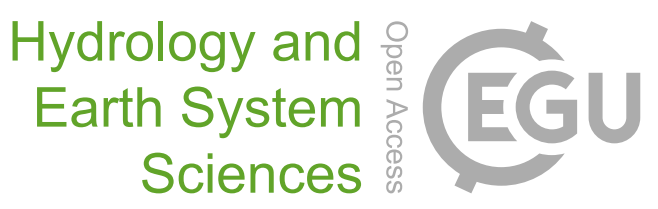

Supplement of

\title{
Participatory flood vulnerability assessment: a multi-criteria approach
}

Mariana Madruga de Brito et al.

Correspondence to: Mariana Madruga de Brito (mariana.brito@uni-bonn.de)

The copyright of individual parts of the supplement might differ from the CC BY 4.0 License. 
Table S1: Characteristics of experts

\begin{tabular}{|c|c|c|c|c|c|}
\hline Characteristic & $\begin{array}{r}\text { Delphi } 1^{\text {st }} \\
\text { round n }(\%)\end{array}$ & $\begin{array}{c}\text { Delphi } 2^{\text {nd }} \\
\text { round n }(\%)\end{array}$ & $\begin{array}{r}1^{\text {st }} \text { focus group } \\
\text { n }(\%)\end{array}$ & $\begin{array}{r}2^{\text {nd }} \text { focus group } \\
\text { n (\%) }\end{array}$ & $\begin{array}{r}\text { Workshops n } \\
(\%)\end{array}$ \\
\hline \multicolumn{6}{|l|}{ Work affiliation $^{*}$} \\
\hline Academy & $57(56.4)$ & $43(44.3)$ & $6(60.0)$ & $4(66.7)$ & $13(48.1)$ \\
\hline Government organizations & $32(31.7)$ & $27(27.8)$ & $1(10.0)$ & $0(0.0)$ & $8(29.6)$ \\
\hline Research institutes & $21(20.8)$ & $19(19.6)$ & $1(10.0)$ & $1(16.7)$ & $4(14.8)$ \\
\hline Business/industry & $9(8.9)$ & $6(6.2)$ & $1(10.0)$ & $0(0.0)$ & $1(3.7)$ \\
\hline NGO & $3(3.0)$ & $2(2.1)$ & $1(10.0)$ & $1(16.7)$ & $1(3.7)$ \\
\hline \multicolumn{6}{|l|}{ Gender identity } \\
\hline Male & $54(53.6)$ & $44(55.0)$ & $2(22.3)$ & $2(40.0)$ & $8(36.4)$ \\
\hline Female & $47(46.5)$ & $36(45.0)$ & $7(77.7)$ & $3(60.0)$ & $14(63.6)$ \\
\hline \multicolumn{6}{|l|}{ Education level } \\
\hline Ph.D. & $56(55.4)$ & $44(55.0)$ & $3(20.0)$ & $4(80.0)$ & $11(50.0)$ \\
\hline Master & $35(34.6)$ & $28(35.0)$ & $4(26.7)$ & $1(20.0)$ & $8(36.4)$ \\
\hline Bachelor & $4(4.0)$ & $3(3.7)$ & $1(6.7)$ & $0(0.0)$ & $2(9.1)$ \\
\hline M.B.A. & $4(4.0)$ & $4(5.0)$ & $0(0.0)$ & $0(0.0)$ & $0(0.0)$ \\
\hline High school & $2(2.0)$ & $1(1.3)$ & $1(6.7)$ & $0(0.0)$ & $1(4.5)$ \\
\hline \multicolumn{6}{|l|}{ Profession $^{*}$} \\
\hline Geography & $27(26.5)$ & $21(25.9)$ & $0(0.0)$ & $0(0.0)$ & $5(21.7)$ \\
\hline Engineering & $25(24.5)$ & $20(24.7)$ & $3(18.8)$ & $4(66.7)$ & $5(21.7)$ \\
\hline Geology & $20(19.6)$ & $16(19.8)$ & $0(0.0)$ & $0(0.0)$ & $2(8.7)$ \\
\hline Others & $8(7.8)$ & $8(9.9)$ & $3(18.8)$ & $0(0.0)$ & $5(21.7)$ \\
\hline Architecture & $5(4.9)$ & $4(4.9)$ & $2(12.5)$ & $1(16.7)$ & $3(13.0)$ \\
\hline Law & $5(4.9)$ & $2(2.5)$ & $0(0.0)$ & $0(0.0)$ & $0(0.0)$ \\
\hline Social sciences and service & $4(3.9)$ & $2(2.5)$ & $1(6.3)$ & $1(16.7)$ & $3(13.0)$ \\
\hline Biology & $3(2.9)$ & $3(3.7)$ & $0(0.0)$ & $0(0.0)$ & $0(0.0)$ \\
\hline Economy & $3(2.9)$ & $3(3.7)$ & $0(0.0)$ & $0(0.0)$ & $0(0.0)$ \\
\hline Meteorology & $2(2.0)$ & $2(2.5)$ & $0(0.0)$ & $0(0.0)$ & $0(0.0)$ \\
\hline \multicolumn{6}{|c|}{ Self-reported knowledge of flood vulnerability analysis } \\
\hline Limited & $0(0.0)$ & $0(0.0)$ & $0(0.0)$ & $0(0.0)$ & $0(0.0)$ \\
\hline Reasonable & $43(42.6)$ & $31(38.8)$ & $3(33.3)$ & $2(40.0)$ & $11(50.0)$ \\
\hline Very good & $58(57.4)$ & $49(61.3)$ & $6(66.7)$ & $3(60.0)$ & $11(50.0)$ \\
\hline Total no. of participants & 101 & 80 & 9 & 5 & 22 \\
\hline
\end{tabular}

*The participants could select more than one work affiliation and profession. Only the professions that were mentioned twice are shown here. The remaining was grouped in the 'others' category. 
Figure S1: Individual vulnerability maps

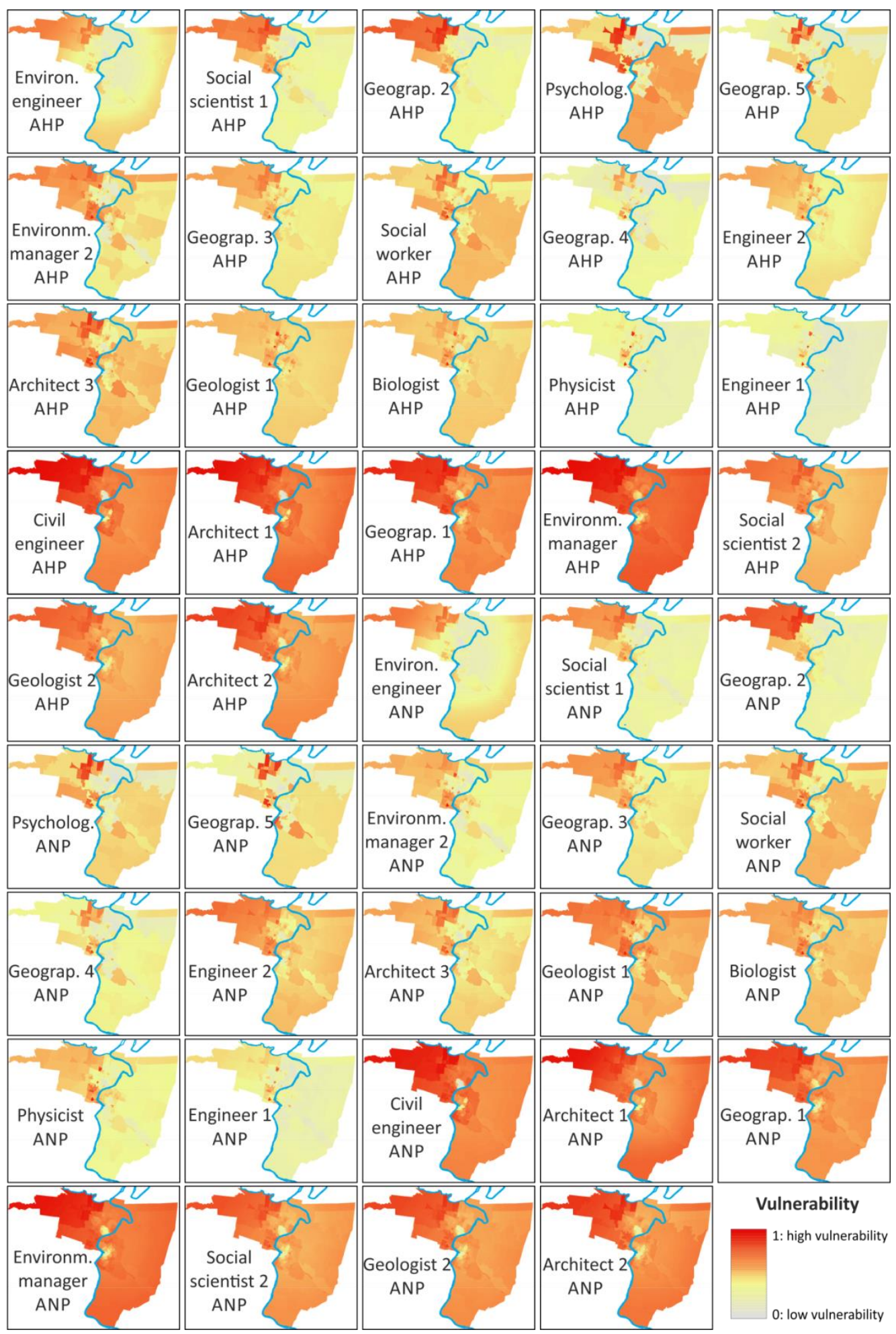

